Research Article

\title{
Development of Data Integration and Sharing for Geotechnical Engineering Information Modeling Based on IFC
}

\author{
Jiaming Wu ${ }^{10},{ }^{1,2}$ Jian Chen ${ }^{D},{ }^{1,2,3,4,5}$ Guoliang Chen, ${ }^{1,2,3,4}$ Zhe Wu, ${ }^{6}$ Yu Zhong, ${ }^{7}$ Bin Chen, ${ }^{4}$ \\ Wenhui Ke, ${ }^{8}$ and Juehao Huang ${ }^{1,2,3,4}$ \\ ${ }^{1}$ State Key Laboratory of Geomechanics and Geotechnical Engineering, Institute of Rock and Soil Mechanics, \\ Chinese Academy of Sciences, Wuhan 430071, China \\ ${ }^{2}$ School of Engineering Science, University of Chinese Academy of Sciences, Beijing 100049, China \\ ${ }^{3}$ Hubei Key Laboratory of Geo-Environmental Engineering, Wuhan 430071, China \\ ${ }^{4}$ The Soft Soil Research Center in Ningbo University of Technology, \\ State Key Laboratory of Geomechanics and Geotechnical Engineering, Ningbo 3 15211, China \\ ${ }^{5}$ China-Pakistan Joint Research Center on Earth Sciences, Islamabad, Pakistan \\ ${ }^{6}$ China State Construction International Holdings Limited, Hong Kong 999077, China \\ ${ }^{7}$ Wuhan Metro Group Co., Ltd., Wuhan 430071, China \\ ${ }^{8}$ Wuhan Municipal Construction Group Co., Ltd., Wuhan 430071, China
}

Correspondence should be addressed to Jian Chen; chenjian@whrsm.ac.cn

Received 10 September 2020; Revised 30 December 2020; Accepted 1 February 2021; Published 13 February 2021

Academic Editor: Wen-Chieh Cheng

Copyright (c) 2021 Jiaming Wu et al. This is an open access article distributed under the Creative Commons Attribution License, which permits unrestricted use, distribution, and reproduction in any medium, provided the original work is properly cited.

With the rapid development of infrastructure construction, geotechnical engineering has always been worthy of attention due to its complexity and diversity. Accelerating the informatization of geotechnical engineering will contribute to the project management, but the information contained in geotechnical engineering cannot be well integrated because of the lack of unified data standards. Building Information Modeling (BIM) has been considered as an effective technology to manage information, and Industry Foundation Classes (IFC) in BIM serves as a neutral and open standard for the exchange of information. However, it was found that BIM cannot express the information of some structure objects and geological objects well during the construction process of geotechnical engineering. Combined with the characteristics of geotechnical engineering, taking advantage of the good extensibility of IFC, this paper proposes a "Built-In Generation Schema" for geotechnical structure models and a "Plug-In Extension Schema" for three-dimensional (3D) geological models, ultimately forming the basic data system of geotechnical engineering information models based on IFC. Applying extended IFC to the modeling process, the BIM-based modeling method of geotechnical models is proposed. In addition, an IFC-based platform is developed to integrate geological models and structure models for further displaying and analyzing of geotechnical engineering models. The work in this paper provides a feasible way and technical support for promoting the integration and sharing of geotechnical engineering information and enhancing the multiprofessional collaborative work.

\section{Introduction}

With the acceleration of social urbanization, the demand for urban infrastructure continues to thrive. Geotechnical engineering is a crucial component of infrastructure construction, and its complexity and diversity have always been worthy of attention [1, 2]. Geotechnical engineering is closely related to geological engineering, structure engineering, and other disciplines. In the process of construction, it often needs multidisciplinary coordination, which will bring challenges to project management [3]. In the whole life of geotechnical engineering, different kinds of information and data need to be acquired timely, which requires rapid processing and integration, real-time feedback, and guidance for construction [4].

Building Information Modeling (BIM) [5], as an innovative concept and method intended to improve 
interoperability in the process of modeling, has swept the global engineering construction industry since the beginning of this century. It is believed that BIM has triggered the second digital revolution in the field of engineering design and construction and promoted the transformation and upgrading of construction-related industries [6, 7]. BIM technology exchanges various types of information of construction projects through an internationally used open data standard Industry Foundation Classes (IFC), which has been gradually considered as the most extensive data standard of BIM since its publication [8]. Due to its good scalability, IFC is an intermediary aimed at realizing crossdomain, cross-specialty, cross-stage, and cross-platform data interaction and sharing, and it is also the key to improve the collaborative operation of BIM system [9].

When viewing from the poor data-exchange performance and information island problem faced by the informatization of geotechnical engineering, the successful experience of BIM technology brings us thinking and enlightenment: can BIM be applied to geotechnical engineering informatization? Can BIM effectively result in better information management for geotechnical engineering? To answer these questions and solve the problem of data information islanding in geotechnical engineering, IFC will be the key due to its good scalability. Hence, in this paper, the first and foremost priority is to apply and extend IFC into geotechnical engineering for data integration and sharing.

Due to the short of the uniform data standard for geotechnical models, it is necessary to extend IFC standard for geotechnical structure and geological model. An IFCbased strategy is established to extend the definition of multisource data in geotechnical engineering into BIM environment. For the IFC-based integrated model, it is intended not only to be used for visually displaying, but also to be extended for numerical calculation and analysis.

\section{Literature Review}

2.1. 3D Geological Model. The construction of geotechnical engineering is inseparable from the mastery and utilization of geological conditions. Researchers from different perspectives proposed many theories and technologies for three-dimensional (3D) geological modeling [10-12]. In order to simulate the complex geological structure, related modeling software has been developed (ArcGIS [13], GoCAD [14], Surpac [15], etc.). These models usually have specific data formats, such as GeoSciML [16] and 3D-GEM [17]. However, these developed data standards are mainly oriented in the 3D Geographic Information System (GIS) field.

In addition, in geotechnical engineering, some computing software is used to build geological models to analyze and evaluate the safety and stability of engineering geological bodies [18]. These geological models are built based on survey data, and many of the strata are simplified, making them relatively simple $[19,20]$. Moreover, when the structural model needs to be considered, most of the calculation add simplified structural units as needed.
To sum up, geological models are mainly considered in traditional geotechnical engineering. Either structure models are not considered, or simplified structure units are considered, but the integration between geological models and structure models is not really realized. Moreover, data exchange and information fusion are not satisfactory, and it is difficult to form a collaborative system that can be integrated and shared. This makes it tough to transfer and share information in the process of geotechnical engineering construction, and it is prone to generate information island problems, which will lead to time delay, cost increase and even safety accidents. The main reason is the lack of unified data standards between the geological model and structure model which cannot be effectively integrated, and information cannot be shared and exchanged.

2.2. Extending the Information Models Based on IFC. With the in-depth research and application of IFC, researchers held the view that the information description of IFC in some professional fields was not complete, and various options for extending the IFC model had emerged accordingly [21]. Extensive efforts were undertaken by Yabuki and Li [22] to implement IFC for infrastructure. For bridge engineering, they extended quite a few IFC entities and created an IFC-bridge information model. For shield tunneling, Yabuki et al. [23] developed an IFC-based product model and applied it to a shield tunnel project to manage some information. Zhou et al. [24] also contributed to extending the application of IFC standard in shield tunnels, making IFC accommodate the segment assembly process. In response to the lack of IFC standards in road engineering, Lee and Kim [25] described the spatial and physical structure elements for the road structure to create the road information model. Lee et al. [26] also proposed the extension mechanism for the NATM tunnel, a data schema aimed at implementing a description of various components based on IFC. More than that, many organizations are also actively promoting the application of IFC in infrastructure engineering, such as the European research project V-Con and French working group MINnD Concepts [27]. Their works have deepened the application of IFC in infrastructure engineering, but so far the scope of these BIM projects is mainly on structure objects. Geology, as the prerequisite and foundation of engineering construction projects, is not fully reflected in IFC framework.

Zhou et al. [28] proposed a metro protection information model (MPIM) based on IFC, which extended the simple geological model and external building model as the foundation for MPIM. Providakis et al. [29] proposed a methodology that the buildings were modeled together with the ground, the subsurface geology, and the tunnel, in which IFC is employed to act as a conversion medium between the BIM data and other analysis tools.

Some preliminary study on geological models based on IFC has been carried out, but its proposed models were mainly used for visualization. There still exists a big gap between current modeling methods and growing demands for integrating geological objects and geotechnical structures 
in a uniform standard and extending the integrated model to carry out geotechnical design and numerical analysis.

On the whole, in order to solve the problem imposed by short of the uniform data standard for geotechnical models, an IFC-based schema is proposed in this paper to better integrate the geological model and structure model. And the extended integrated model fully considers the characteristics of geotechnical engineering, which can not only be visualized but also meet the requirements of geotechnical design and numerical analysis.

\section{Geotechnical Engineering Informatization}

Different from traditional building engineering, geotechnical engineering is both building engineering and geological engineering. The two core elements in geotechnical engineering are the geological body and engineering structure, which interact with and influence each other. The geological body is not only the carrier of geotechnical engineering structure, but also the object of construction and reconstruction. In addition, the geological body is strengthened and protected by the engineering structure. The structure is in general man-made, while the ground is nature-generated. That is, the man-made structures and natural geological settings comprise the backbone of geotechnical modeling, but they have totally different features.

There are many kinds of structures used in geotechnical engineering, such as underground diaphragm wall, bored pile, reinforced concrete support, steel support, anchor rod, steel arch, and shield segment. Geotechnical structures have the same features as those defined in BIM models, as they are all man-made or designed by our engineers. Geotechnical structures and general building structures are in the same line in essence, and it is relatively straightforward to reach a consensus on the model implementation mechanism and specific expression form. Therefore, it is natural for geotechnical structures to adopt IFC and BIM technology for modeling.

However, the big difference exists between the geological models and the BIM models. The geological model is made by engineering designers according to the speculation of discrete geological survey points, while the BIM structure model is created by designers. Not only that, but 3D geological modeling is mostly applied in visualization but has not been deeply applied in the practical application of geotechnical engineering, just like the "good-looking but useless" evaluation by many engineering implementers, which reduces the utilization value of information.

Considering the growing demand for big data integration and sharing in geotechnical engineering, the application of BIM technology is expected to realize the collaborative systemization of geotechnical engineering software. The big obstacle is that the data standard is not unified between geological models and BIM models, and they need to reach a consensus. For geotechnical structure, it is natural to utilize the existing entities in current IFC standard due to the similar features as those defined in BIM models. However, for geological model, IFC standard will be used as the intermediate bridge of data conversion to accommodate the demands of geological modeling in BIM environment. It could be an efficient method to solve the problem of inconsistency of current data standards.

In order to generate geotechnical structure information in the BIM domain, we will build corresponding components in terms of entity and relationship using the inherent components in IFC classes. So we can call this "Built-In Generation Schema," while, for geological data, it has not been considered in IFC framework before. We need to create new IFC entities for them by extending IFC data structure. Also, there will be some new entities and relationships established in IFC framework. The data model for geological data will be included into IFC framework using its extension mechanism. Compared to the geotechnical structure, we then call this "Plug-In Extension Schema" for geological modeling. And then, an integrated BIM model for geotechnical engineering is formed by the two based on IFC. Based on the proposed data generation mechanism under IFC framework, the integrated BIM model helps us overcome the lack of unified data standard between the geological model and structure model. On this basis, we use the integrated model to serve the geotechnical design.

\section{Data Integration and Sharing Mechanism Based on IFC}

4.1. IFC Data Schema. The most indispensable concept in IFC is the entity, a class of objects defined with common properties. It is produced in an object-oriented manner, expressing information by means of defining attributes and attaching constraints to attributes. IFC framework has a distinctive hierarchy and modular characteristics, the data schema architecture of which is split into four layers, namely, domain layer, interoperability layer, core layer, and resource layer. The core layer includes kernel schema and core extension schema, which serves to ensure the sustainability of the model and assist the entity update. IFC standard provides three extension mechanisms: entity extension, IfcProxy-based entity definition, and extended property set [27].

As the most crucial entity in the core layer, IfcRoot is the root entity that implements other entities in the core layer, the interaction layer, and the domain layer. As Figure 1 shows, IfcObjectDefinition, IfcRelationship, and IfcPropertyDefinition are three considerable subclasses of IfcRoot. IfcObjectDefinition is a definition form of IFC objects, and IfcObject derived from it defines the object entities in the IFC standard [26]. IfcProduct, as a subtype derived from IfcObject, can be used to represent the tangible or objective entities involved in the construction process. And it explicitly defines the spatial structure entity IfcSpatialStructurElement and physical entity IfcElelement that constitute the project object. IfcRelationship, defining the relationship between all objects derived from IfcObject, through its various subtypes, can integrate the newly added entities into the IFC framework. IfcPropertyDefinition is a property definition entity, which represents a generalization of the properties of a specific object. Its subtype IfcPropertySetDefintion defines a property set. 


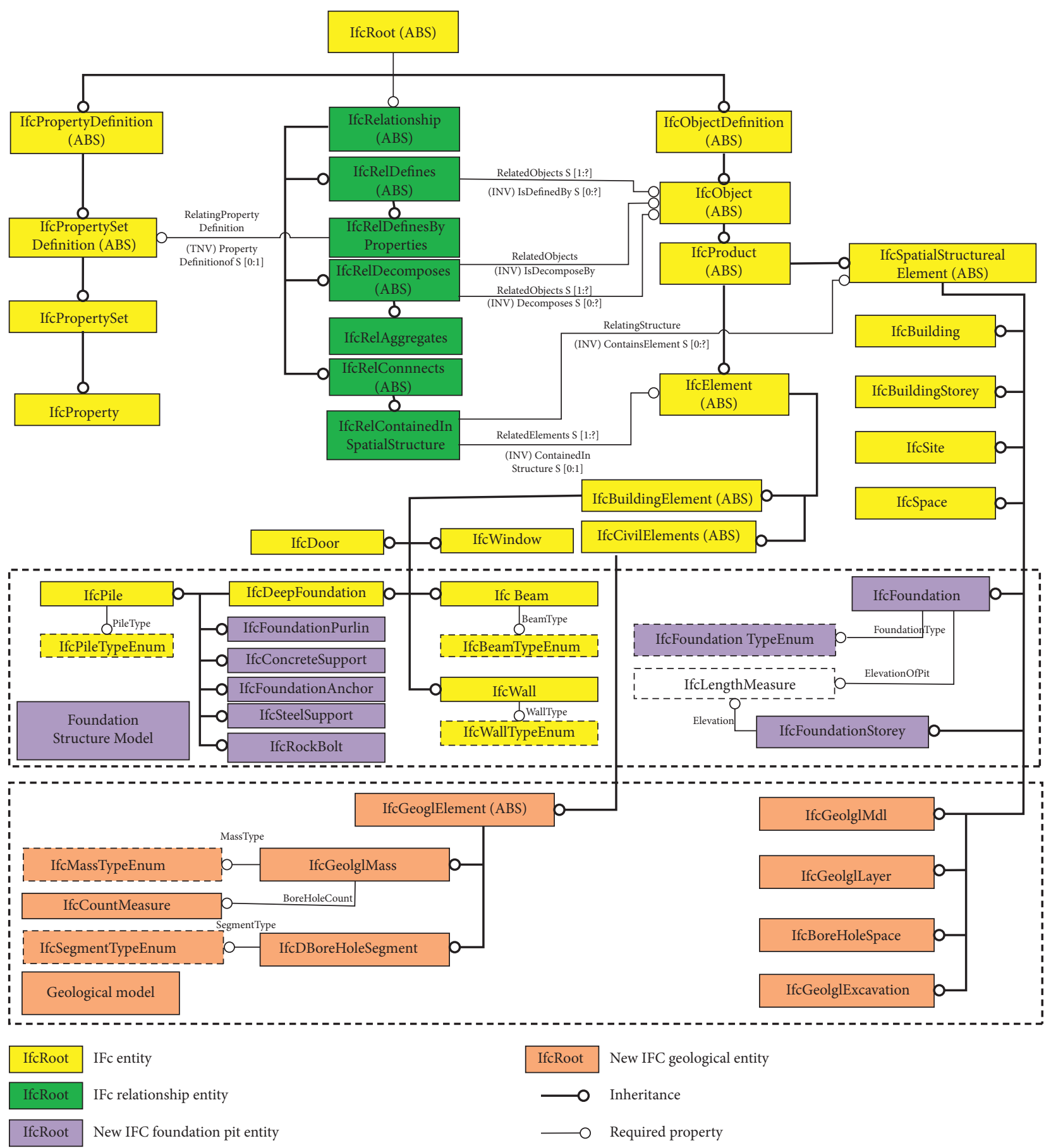

FIgURE 1: IFC extended EXPRESS-G diagram of the geotechnical information model.

To extend geotechnical engineering information in accordance with IFC standards, taking geotechnical engineering characteristics and model requirements into account is indispensable. For a specific object in geotechnical engineering, we select a subtype derived from IfcObject as its supertype and assigning properties to it. As for the relationship types between objects, we associate one corresponding subtype of IfcRelationship and define the property of the relationship entity. According to specific requirements of the project, the entity dynamic properties are extended through IfcPropertySet. Moreover, IfcPropertySet is associated with the subclass entity of the main entity IfcObject through the relationship entity IfcRelDefinedByProperties, which makes abstract objects concrete.

\section{2. "Built-In Generation Schema” for Geotechnical Structure.} Geotechnical engineering structures have common characteristics with general building structures. For this reason, the entity description of the geotechnical engineering 
structure can inherit and reference the building structure entity in the existing IFC data schema. In the IFC framework, IfcBuildingElement is used to define and represent some common building components in the building field. For extending the geotechnical structure entities, an abstract entity representing the physical element of geotechnical structure is added under the IfcBuildingElement. Some of the components in the newly added subtype can call existing entities, and some need to be newly defined and described. This is what we call "Built-In Generation Schema."

Foundation structures, acting as a typical representative in geotechnical engineering, are herein used to describe this extension mechanism. When it comes to the current edition, the deep foundation entity IfcDeepFoundation has been included as a subtype of IfcBuildingElement. In consequence, the foundation structure object can inherit and call IfcDeepFoundation. And some of the foundation components that have not yet been included can be defined directly under the IfcFoundation, which is shown in Figure 1.

4.2.1. Representation of the IFC-Based Physical Element. Taking the retaining structure system of fender pile and internal support as an example, the main components are cast-in-place pile, crown beam, concrete support, steel support, steel purlin, and anchor cable (pole). To be specific, the crown beam entity inherits directly from the IfcBeam, which is derived from IfcBuildingElement, utilizing its enumeration type to represent the crown beam category, as shown in Table 1. As for the cast-in-place pile entity, it calls IfcPile, which is a subtype of IfcDeepFoundation, and uses its enumeration type for category description. Other components are defined as subtypes of IfcDeepFoundation, and information is extended by the means of defining entity type, including IfcConcreteSupport, IfcSteelSupport, IfcRockBolt, and IfcFoundationPurlin.

4.2.2. Representation of the IFC-Based Spatial Structure Element. IfcSpatialStructureElement is the supertype of all spatial structures in IFC, decomposing the project model into various suitable subsets according to the spatial layout. Although spatial description types such as IfcBuilding, IfcBuildingStory, IfcSite, and IfcSpace already exist in IFC, they are all designed for building engineering. Accordingly, IfcFoundation and IfcFoundationStorey are added as the spatial structure entity to specifically describe the foundation structure.

With the effect of providing characteristic data of foundation structure, IfcFoundation involves location, spatial geometry, depth, and some other information. The basic characteristics of the structure system type and relative elevation are expressed by FoundationType and ElevationOfFoundation. The enumeration type OfFoundationType is IfcFoundationTypeEnum, which is defined as follows:
TYPE IfcFoundationTypeEnum = ENUMERATION OF (ROW_PILE, DIAPHRAGM_WALL, SHEET_PILE, SMW, USERDEFINED, NOTDEFINED); END_TYPE;

As the spatial part corresponding to each layer of foundation, IfcFoundationStorey describes the spatial location, spatial geometry, and other information of each layer of foundation structure in view of the support location of each layer. The relation entity IfcReggregates is the indispensable bridge connecting the hierarchical relations among the spatial structure elements of the foundation. The vertical hierarchical relationship of the foundation spatial structure element is shown in Figure 2. The IfcSite is located in the global coordinate system of IfcProject, where IfcFoundation is located in IfcSite, IfcFoundationStorey may include multiple adjacent layered spaces as a complex to form a complex type, or it may only contain a single-layered space to form an element type.

4.3. "Plug-In Extension Schema" for the Geological Model. As mentioned above, in view of the common characteristics of foundation structure and BIM structure, we proposed the "Built-In Generation Schema." The current IFC framework is mainly for building structures. However, conspicuous differences between 3D geological model data and BIM structural data that have been identified have impeded the adoption of geological model data into IFC framework. In order for geological model data to be integrated into IFC, it is urgently needed to create new entities, describe new relationship characteristics, and extend new information types. In consideration of the fact that IfcCivilElement has been added in IFC4 to describe entities of civil engineering objects, we can directly add IfcGeolglElement under IfcCivilElement to express the geological model. All components of IfcGeolglElement need to be newly added. Accordingly, we put forward the IFC-based "Plug-In Extension Schema" for the geological model.

A typical 3D geological model consists of geological objects such as strata, strata block, obstacles, underground cavities, and so on. In this paper, the blocks, obstacles, and underground cavities are classified into a class of objects, collectively referred to as geological mass, through the types of which actual objects can be distinguished. The ultimate goal of creating the geological model is to define the IFC elements of these geological objects, the relationships between them, and the property information of the geological objects. Its overall framework is shown in Figure 3. The newly added geological IFC objects include geological physical elements and geological spatial structure elements. It is the relationship entity IfcRelContainedInSpatialStructure that connects geological physical elements with geological spatial structure elements, while the relationships between geological spatial structure elements are established through IfcRelAggregate. The layered characteristics of rock 
TABLE 1: Representation of foundation components.

\begin{tabular}{|c|c|c|c|}
\hline Element & Crown beam & IFC entity & IfcBeam \\
\hline Type & \multicolumn{3}{|c|}{$\begin{array}{l}\text { TYPE IfcBeamTypeEnum = ENUMERATION OF (FIXED_SECTION, VARIABLE_SECTION, USERDEFINED, } \\
\text { NOTDEFINED); END_TYPE; }\end{array}$} \\
\hline Shape & IfcExtrudedAreaSolid & $\begin{array}{l}\text { Section } \\
\text { Contour }\end{array}$ & IfcParameterizedProfileDef \\
\hline PropertySet & \multicolumn{3}{|l|}{ Pset_Beam } \\
\hline Element & Fender pile & IFC entity & IfFoundationPile \\
\hline Type & $\begin{array}{l}\text { TYPE IfcPileTypeEnum = ENUMERATION OF (CAST-IN-PLACE, IMPACT- } \\
\text { CONE, DIGGING, USERDEFINED, NOTDEFINED); END_TYPE; }\end{array}$ & & \\
\hline Shape & IfcSectionedSpine & $\begin{array}{l}\text { Section } \\
\text { Contour }\end{array}$ & IfcParameterizedProfileDef \\
\hline PropertySet & \multicolumn{3}{|l|}{ Pset_Pile } \\
\hline Element & Steel support & IFC entity & IfcSteelSupport \\
\hline Type & \multicolumn{3}{|c|}{$\begin{array}{l}\text { TYPE IfcSteelSupportTypeEnum = ENUMERATION OF (STEEL_TUBE, FASHIONED_IRON, USERDEFINED, } \\
\text { NOTDEFINED); END_TYPE; }\end{array}$} \\
\hline Shape & IfcExtrudedAreaSolid & $\begin{array}{l}\text { Section } \\
\text { Contour }\end{array}$ & IfcParameterizedProfileDef \\
\hline PropertySet & \multicolumn{3}{|l|}{ Pset_SteelSupport } \\
\hline Element & Concrete support & IFC entity & IfcConcreteSupport \\
\hline Type & \multicolumn{3}{|c|}{$\begin{aligned} \text { TYPE IfcConcreteSupportTypeEnum = } & \text { ENUMERATION OF (STRAIGHT_LINE, CURVE, USERDEFINED, } \\
& \text { NOTDEFINED); END_TYPE; }\end{aligned}$} \\
\hline Shape & IfcExtrudedAreaSolid & $\begin{array}{l}\text { Section } \\
\text { Contour }\end{array}$ & IfcParameterizedProfileDef \\
\hline PropertySet & \multicolumn{3}{|l|}{ Pset_ConcreteSupport } \\
\hline Element & Foundation purlin & IFC entity & IfcFoundationPurlin \\
\hline Type & \multicolumn{3}{|c|}{ TYPE IfcFoundationPurlinTypeEnum = ENUMERATION OF (USERDEFINED, NOTDEFINED); END_TYPE; } \\
\hline Shape & IfcExtrudedAreaSolid & $\begin{array}{l}\text { Section } \\
\text { Contour }\end{array}$ & IfcParameterizedProfileDef \\
\hline PropertySet & \multicolumn{3}{|l|}{ Pset_FoundationPurlin } \\
\hline
\end{tabular}

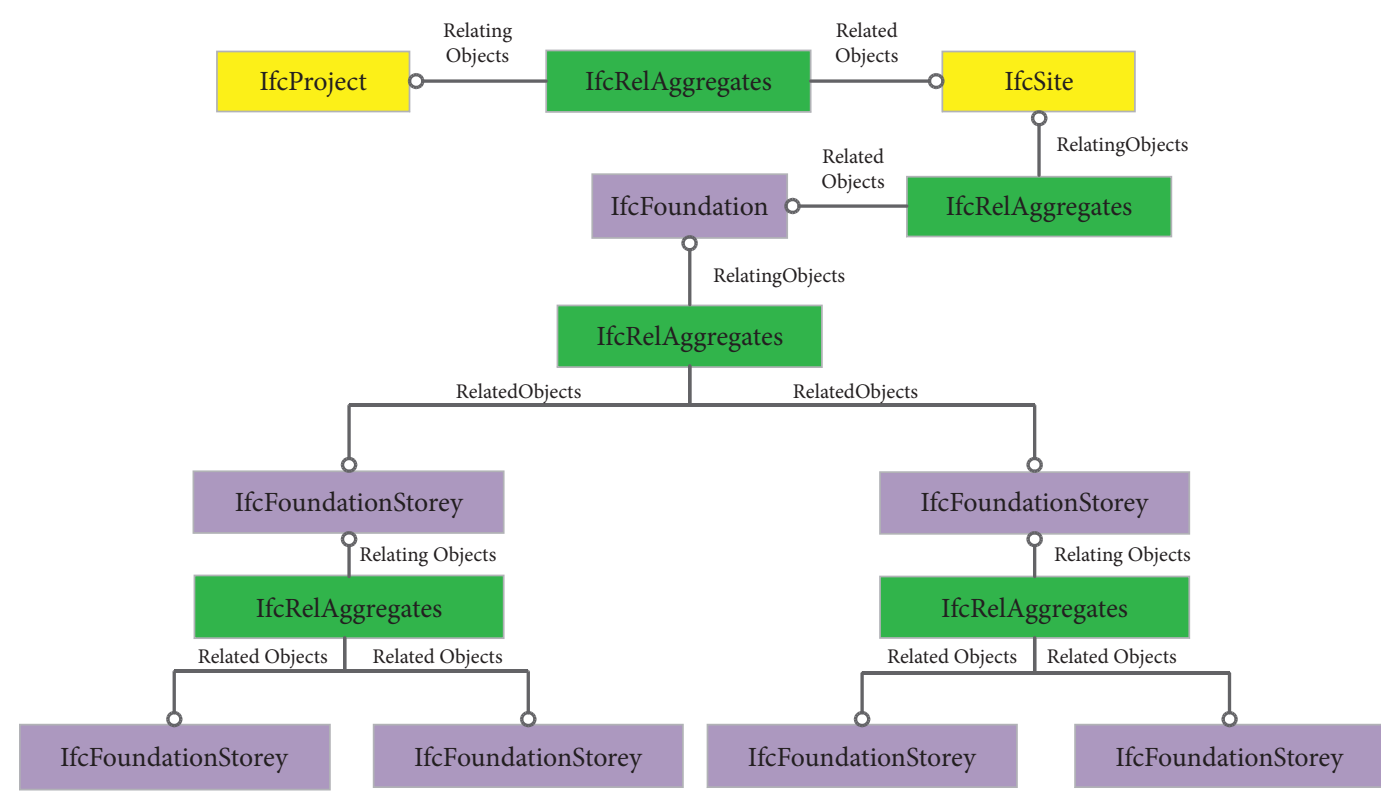

Figure 2: Hierarchical relationship of structure model spatial structure elements.

and soil, as well as physical, chemical, mechanical property, and other property information of the new entity, are realized by extending IfcProperty and the property set IfcPropertySet.
4.3.1. Representation of the IFC-Based Physical Element. Taking the representation characteristics and modeling requirements of geological model data into account, while referring to the structure model description and extension 


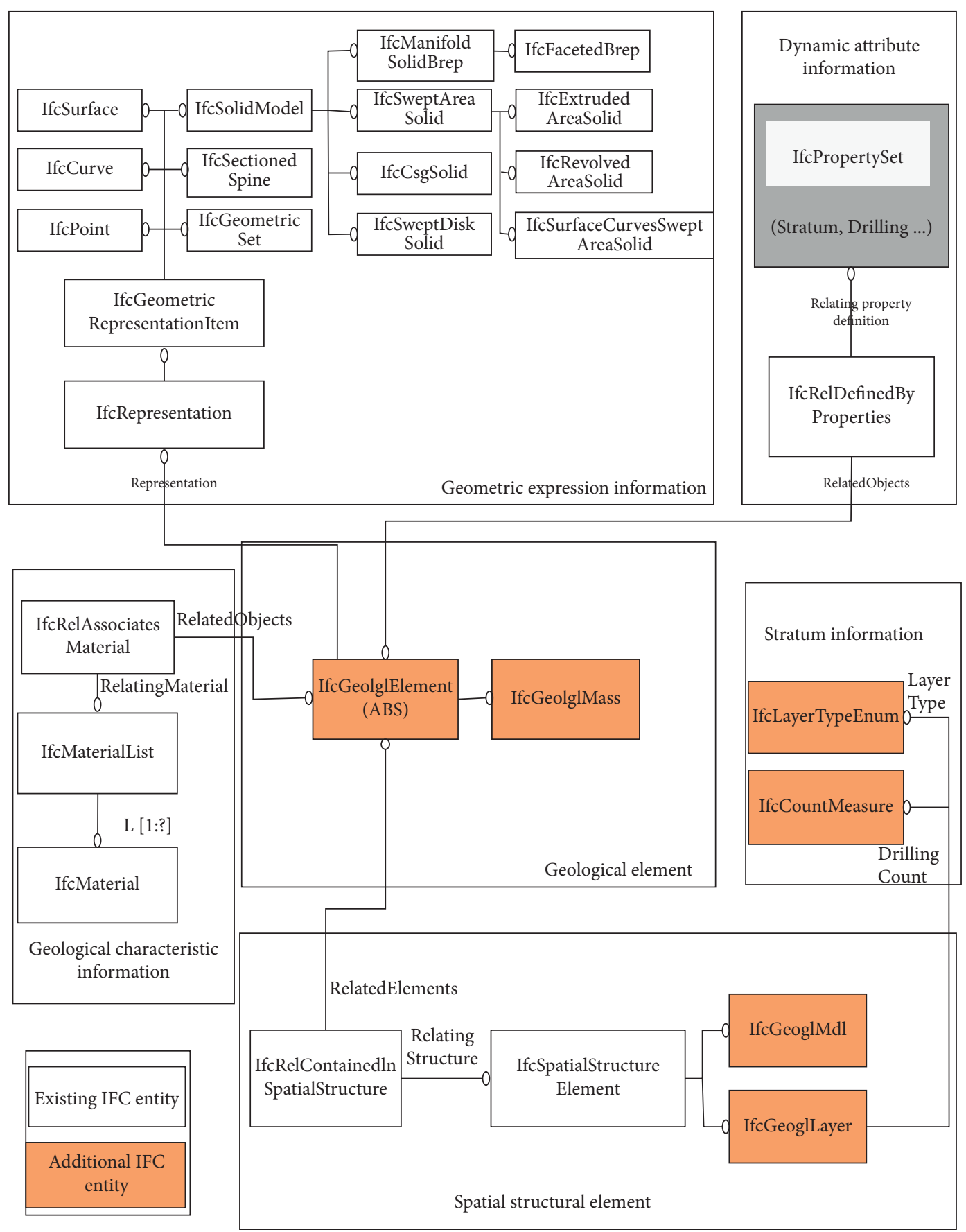

FIgURE 3: The EXPRESS-G diagram of the geological information model based on extended IFC.

mechanism in IFC, we choose to add a geological entity IfcGeolglElement as an abstract subtype derived from IfcCivilElment to describe geological objects. The geological block entity IfcGolglMass is derived from IfcGolglElement, and the same stratum is composed of one or more IfcGolglMass. The hierarchical relationship is shown in Figure 3. In addition, to distinguish ordinary stratigraphic blocks from boulders or cavities, IfcGolglMassEnum is defined for representation, and its express specification is as follows:
TYPE IfcGeolglMassEnum $=$ ENUMERATION OF (STATUM, BOULDER, CAVITY, NOT DEFINED); END_TYPE;

4.3.2. Representation of the IFC-Based Spatial Structure Element. As new entities derived from the abstract supertype IfcSpatialStructureElement, the geological model entity IfcGeolglMdl and the stratum entity IfcGeolglLayer are defined to describe various spatial conceptual entities in the 
geological model, as shown in Figure 4. More specifically, IfcGeolglMdl describes the space occupied by the underground geological body, while IfcGeolglLayer is a spatial entity composed of geological blocks with the same properties in the geological space.

4.3.3. Relationship between Entities. The relationship between entities includes the relationship between spatial entities and the relationship between spatial entities and physical entities. Figure 4 demonstrates the relationship between spatial entities, where IfcRelAggregates plays an essential role in connecting the relationship between IfcGeolglMdl and IfcGeolglLayer. One IfcGeologicalMdl is aggregated from one or more IfcGeolglLayer. Meanwhile, one IfcGeolglLayer can also contain multiple IfcGeolglLayer. For example, age stratification consists of multiple lithologic strata. Figure 5 gives a specific representation of the relationship between spatial entities and physical entities. The relationship between IfcGeolglLayer and IfcGeolglMass is expressed by IfcRelContainedInSpatialStructure, and one IfcGeolglLayer could further contain one or more IfcGeolglMass.

4.3.4. Property. Stratigraphic property information mainly contains two types: one is the layered characteristics of rock and soil, including relevant information such as strata age, lithology, state, and thickness of the stratum; the other is the geophysical and mechanical property, which refers to the relevant physical and mechanical parameter information and geotechnical characteristics by the method of experiments. For expressing these two types of property information, we extend IfcPropertySet and IfcProperty. The definitions of stratum property and property set created in this paper are shown in Tables 2 and 3.

\section{Modeling Method for Geotechnical Engineering Based on IFC Standard}

According to the proposed IFC-based strategy, and "Built-In Generation Schema" for geotechnical structure and "Plug-In Generation Schema" for the geological model, in this section, we will develop corresponding methods to build a geotechnical engineering information model that can accurately describe and display the various information based on IFC using $\mathrm{C}++$ language.

5.1. Modeling Foundation Structures. By compiling the extended IFC standard, the parameters required to describe each type of component of the foundation retaining structure are obtained, which are generally the identification number, name, description, geometric shape expression, category, associated element, property set, and so on. When creating component models, we use the modeling software API to read these parameters, and then call the IFC analysis module to create the IFC type of the corresponding component instance and associate these parameters. In this way, the components in the IFC information model output by the foundation structure model can be organized according to the data standard extended in this paper, so as to realize the information sharing based on IFC.

There are a number of foundation structure types. The modeling method changes depending on the types of the structure components. In order to reduce the modeling workload, as well as shorten the modeling cycle, this paper presents a method of creating a "foundation structure model library." To be specific, a parametric modeling technology is adopted to create a BIM template library for different components for the structure system, thus forming a general structure model library. The main modeling process is illustrated in Figure 6.

Based on the Visual Studio platform, secondary development is employed to implement the foundation structure modeling module based on IFC standard and BIM technology. In consideration of the modeling process, referring to the "Built-In Generation Schema" for geotechnical structure, the organizational framework of the procedure in this paper is established. Figure 7 demonstrates a specific description of the implementation process. The module mainly includes component modeling parameter information, structure element, property definition, and IFC entity read-write submodule. On the consideration of the requirements of the IFC data model, modeling parameter information management part is mainly to set the input component parameters to establish a special data management class, so as to be convenient to call. In the structure element modeling part, based on the "Built-In Generation Schema," all component classes (pile, support, crown beam, etc.) are derived from the FoundationElement class, and all of them can call the corresponding data management class. Additionally, the method functions for component models are created in this part, and relationships between components are established through RelConnectsElement class. Making use of the RelDefinesByProperties class, the definition of the dynamic properties of the foundation component is implemented. Last but not least, the IFC entity read-write submodule has two functions. The first function is to read the IFC file and analyze the parameters needed for component modeling to form a component model. The second objective, on the grounds of the parameters required to describe the IFC entity of each component, is to convert each component class to the IFC entity to form an IFC file.

5.2. Building a 3D Geological Model. We rely on GeoFrame, a self-developed 3D geological modeling platform, to build a 3D geological model. In this platform, a 3D solid model and its properties are combined to form 3D elements, among which a $3 \mathrm{D}$ solid model is composed of the body (simple and complex), surface (simple and complex), ring, triangle, edge, node, and point conceptual models. The $3 \mathrm{D}$ vector spatial data model is oriented to geological entities as a whole and has a clear hierarchical structure inside the entity. It can perform spatial analysis inside the entity, which is convenient for maintenance operations such as model updating and modification. The geological data model abstracts geological entity into four basic elements of 3D space, point, 


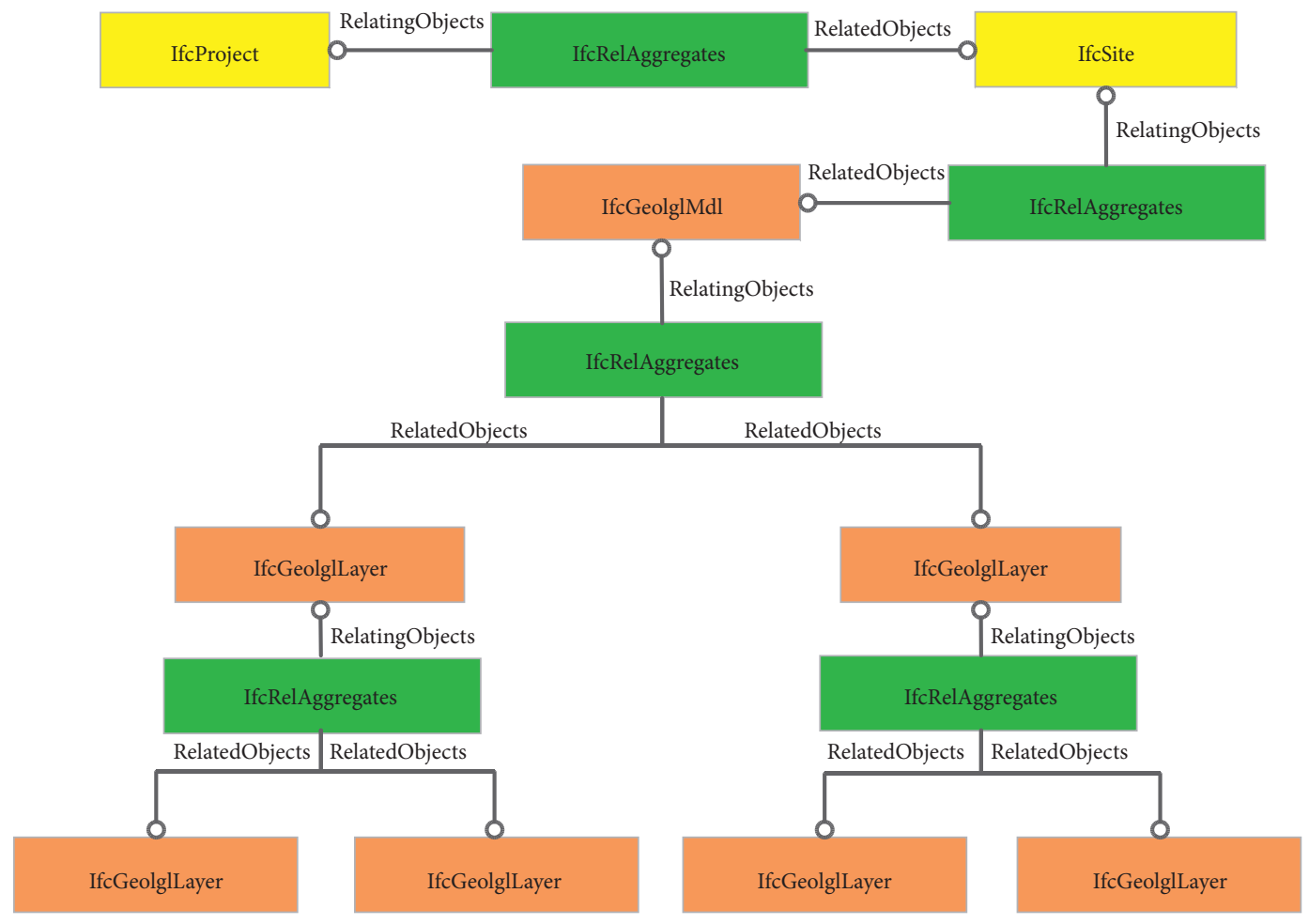

FIGURE 4: Hierarchical relationships of geological model spatial structure elements.

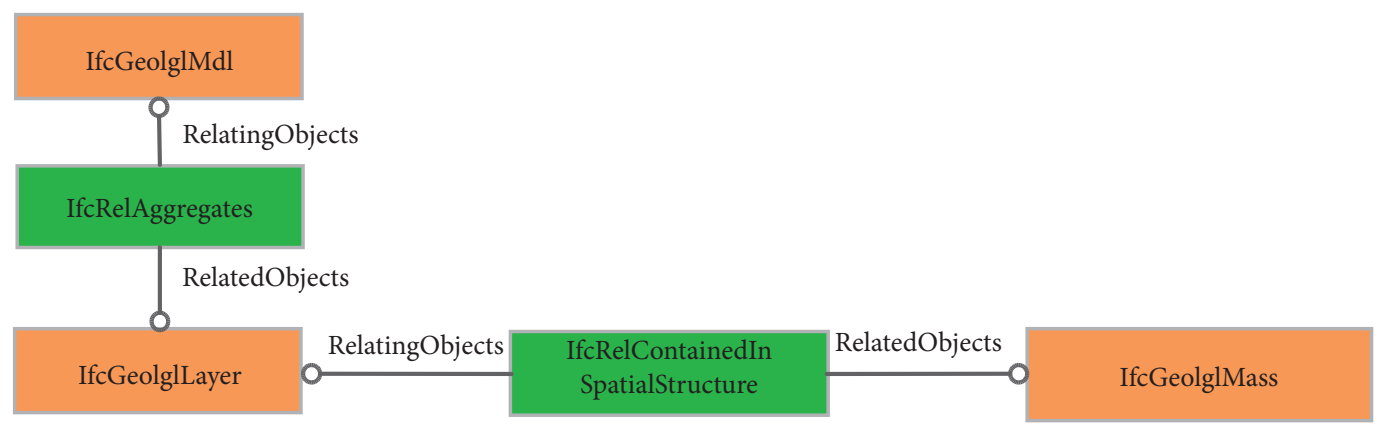

FIGURE 5: Relationships between the physical elements and spatial elements.

TABLE 2: Stratum public IFC property definition.

PropertySet name: Pset_GeolglLayerCommon

Applicable entities: IfcGeolglLayer

Property name

Property type

StratumCode

IfcPropertySingleValue

IfcPropertySingleValue

IfcPropertySingleValue

Geologicalithology

IfcPropertySingleValue

IfcPropertySingleValue

FeatureDescription

IfcPropertySingleValue

TopDepth

IfcPropertySingleValue

BottomDepth

IfcPropertySingleValue

DistributionCharacteristics

IfcPropertySingleValue

Property data type

IfcLabel

IfcLabel

IfcLabel

IfcLabel

IfcLabel

IfcLabel

IfcLabel

IfcLabel

IfcLabel 
TABLE 3: Stratum physical IFC property definition.

\begin{tabular}{lcc}
\hline & $\begin{array}{c}\text { PropertySet Name: Pset_GeolglLayerPhysical } \\
\text { Applicable entities: IfcGeolglLayer } \\
\text { Property name }\end{array}$ & Property type \\
Density & IfcPropertySingleValue & Property data type \\
WaterContent & IfcPropertySingleValue & IfcNumericMeasure \\
VoidRatio & IfcPropertySingleValue & IfcNormalizedRatioMeasure \\
ElasticityModulus & IfcPropertySingleValue & IfcNumericMeasure \\
TensileStrength & IfcPropertySingleValue & IfcNumericMeasure \\
CompressiveStrength & IfcPropertySingleValue & IfcNumericMeasure \\
ShearStrength & IfcPropertySingleValue & IfcNumericMeasure \\
Saturability & IfcPropertySingleValue & IfcNumericMeasure \\
Permeability & IfcPropertySingleValue & IfcNormalizedRatioMeasure \\
PoissonRatio & IfcPropertySingleValue & IfcNumericMeasure \\
Engineering geological characteristics & IfcPropertySingleValue & IfcNumericMeasure \\
\end{tabular}

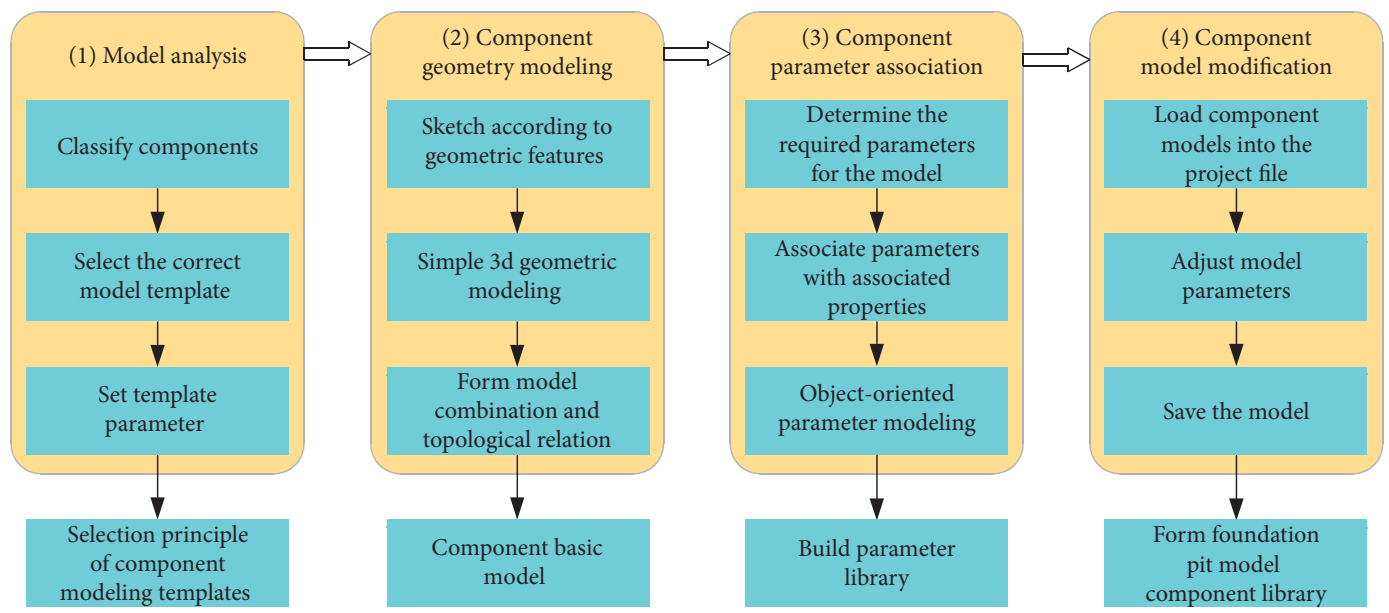

Figure 6: Modeling steps of structure components.

line, surface, and body, and explicitly constructs more complex objects with the geometry of these basic elements.

By virtue of the fact that both the geological model object and IFC model object belong to semantic model, geometric analysis, information extraction, and data conversion can be adopted for the geological model object to realize the conversion of information. Furthermore, by the means of reconstructing the data, based on the "Plug-In Extension Schema" for the geological model, the transformation between the geological model and the IFC model is realized. In order to guarantee the integrity of geometry information in the process of data transformation, IFC geological model is also subdivided into point, line, and surface elements, and mapping relationship is established with the elements of the geological model. The mapping relationship of model elements is shown in Figure 8.

In terms of geometric expression, due to the irregular geometry of the geological body, boundary representation is adopted to describe geological model objects. Likewise, the IFC model can make use of boundary representation to describe and form a geometric entity through the combination of multiple boundary surface patches. In IFC standard, the abstract base class of geometric entities based on boundary representation is IfcManifoldSolidBrep. Its subtype IfcAdvancedBrep corresponds to the boundary enclosed by the spline surface. IfcFacetedBrep, also as its subtype, can describe the entity represented by the boundary surrounded by polygons. In our 3D geological model based on the "Plug-In Extension Schema," IfcFacetedBrep is applied to express the geometric information of IfcGeolglMass with uniform internal characteristics. For IfcGeolglMass containing boulders or cavities inside, IfcFacetedBrepWithVoids, a subtype of IfcFacetedBrep, is extended to describe.

Based on the above comparative analysis of the geological model and IFC model, a special IFC output plug-in is developed with $\mathrm{C}++$ language. By analyzing the 3D geological model established in GeoFrame and taking advantage of the "Plug-In Extension Schema," the IFC entities and related properties are created, and the information flow in the form of a string is generated according to the definition of the IFC standard and output into a standard STEP format file. As a consequence, the output of physical files of the geological model based on the "Plug-In Extension Schema" is realized, which lays a solid foundation for the integration of the geological model and structure model. 


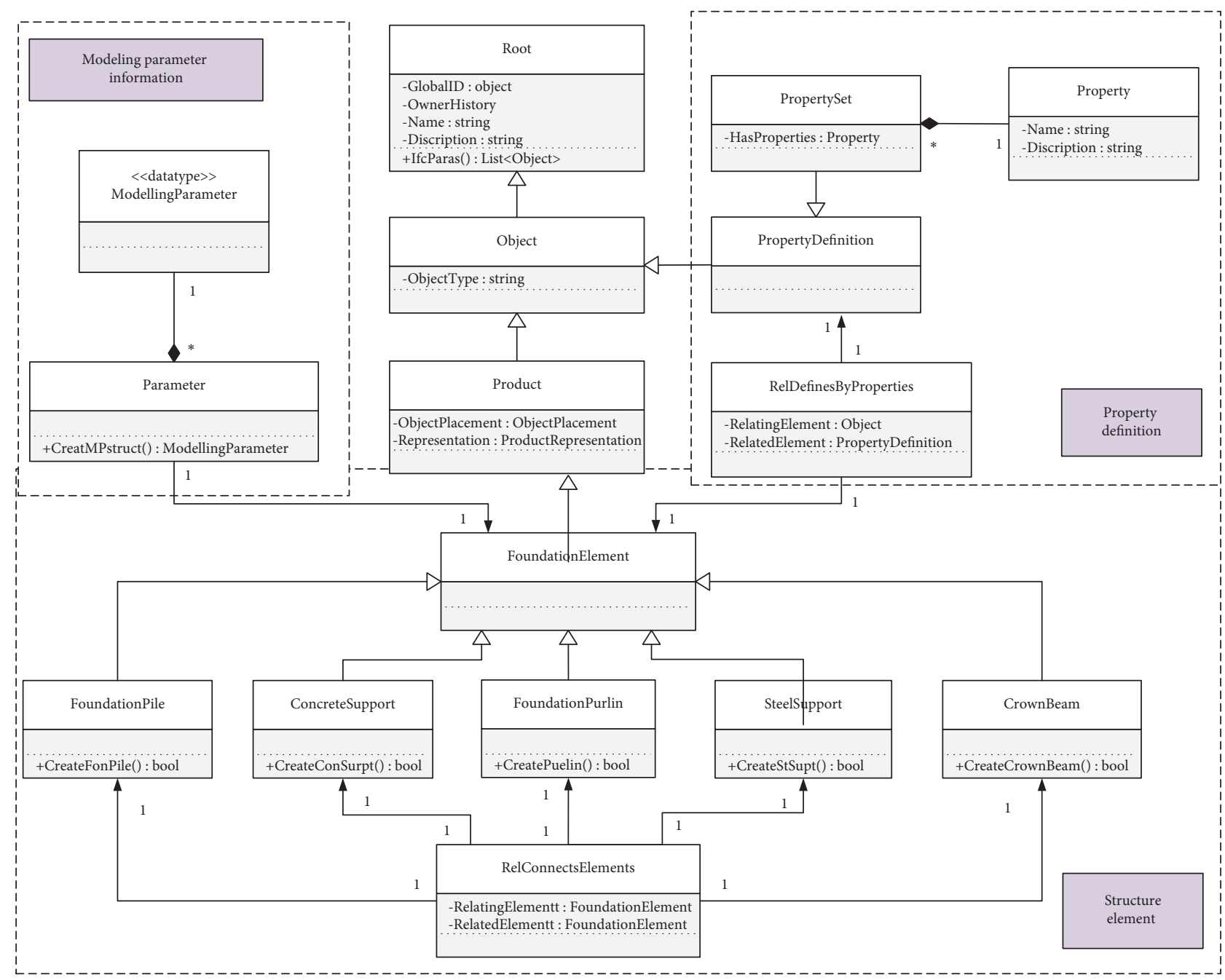

FIGURE 7: Logical structure of IFC-based foundation structure modeling.

\section{Example}

In this section, we will take a metro station in a city as an example to verify the validity of the basic data system and modeling methodology of the geotechnical engineering information model proposed in this paper. In the example, we will build the foundation structure model and 3D geological model based on the extended IFC standard and integrate them on the basis of IFC standard.

The metro station is a two-level underground island-type station with a closed frame structure, which adopts an opencut method. The support structure system of fender pile and internal support is intended for the construction of the foundation. The first layer of lateral support is reinforced concrete, while the second and third layers of lateral support are steel tubes. The connection between steel supports and fender piles are the purlins, which are sustained by angle steel supports. In particular, in order to ensure the stability of the end well, it is prerequisite to set up concrete diagonal bracing and steel tube diagonal bracing. Making use of the
"Built-In Generation Schema," the basic models and the overall model built by parametric modeling are displayed in Figures 9 and 10. By analyzing the 25 geological boreholes obtained in the previous investigation in this area, it is revealed that the stratum mainly consists of 13 lithologic soil layers such as plain fill, residual soil, and granite. Figure 11 presents a geological model built in GeoFrame using borehole survey data. According to the geological objects defined previously based on the "Plug-In Extension Schema," the geological model is exported to the STEP format file.

By the lights of IFC++ open-source tools, using $\mathrm{C}++$ language for secondary development, an IFC integration platform was developed. By analyzing the implementation mode of IFC standard and adopting the method of Early Binding, the data structure based on EXPRESS under IFC core module was implemented as the corresponding $\mathrm{C}++$ class, and finally the C++ class library of IFC standard was formed. We then developed a module for reading and writing IFC files specifically for Express expression, which 


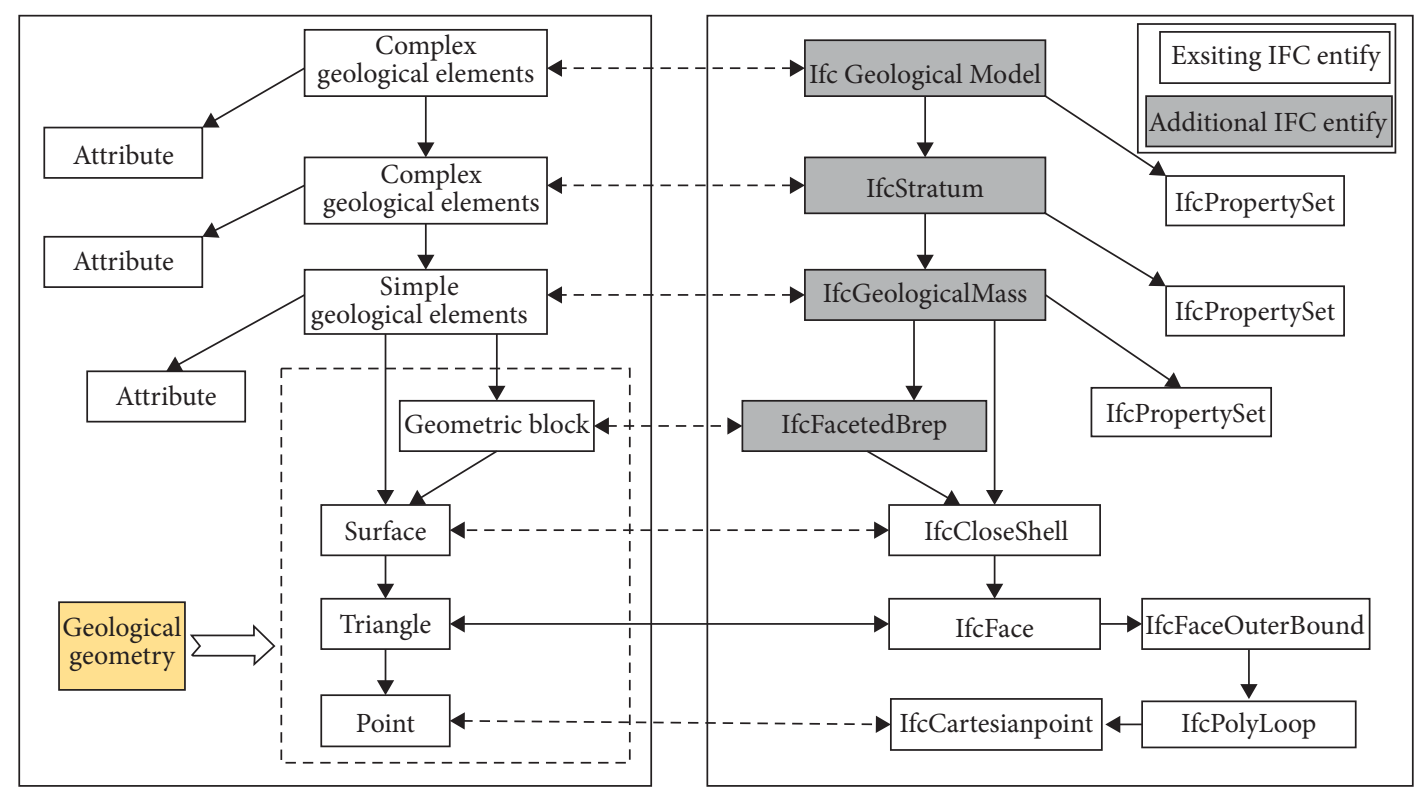

Figure 8: Map of the geological model and IFC model elements.

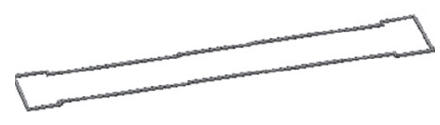

(a)

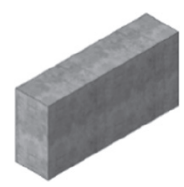

(d)

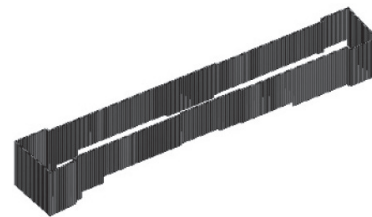

(b)

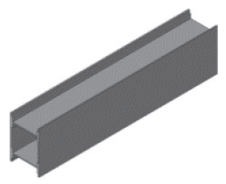

(e)

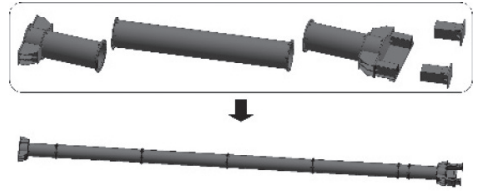

(c)

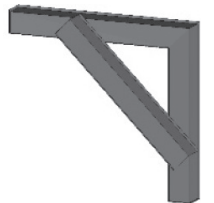

(f)

Figure 9: Models of main structure components. (a) Crown beam. (b) Fender pile. (c) Steel support. (d) Concrete support. (e) Steel purlin. (f) Steel bracket.

was used to transform IFC physical files and the corresponding IFC core classes. Moreover, based on OSG 3D display engine, 3D model display function was developed, used to display the IFC geometric entities. In order to facilitate data creation, viewing, and deletion, the IFC structure tree expression pattern was built according to the IFC data structure hierarchy. This platform realized the functions of viewing 3D geometric model, transforming multiple IFC files, and integrating different professional model files. It is also scalable to be able to connect many professional software.

The STEP file of 3D geological model based on the output of the "Plug-In Extension Schema" is imported into the platform for display, and the structure model in the form of IFC files is synchronously imported into the platform, so as to implement the integration of geotechnical engineering models in Figure 12. Fully considering the characteristics of geotechnical engineering, the integrated BIM model is interactively processed. The integrated BIM model is extended to generate numerical meshes for geotechnical computations and then can be carried out geotechnical design and numerical analysis, as shown in Figure 13.

According to the proposed IFC-based schema, geological models and geotechnical structure models are integrated as shown in Figure 12, which helps us overcome the lack of unified data standard between the geological model and structure model and makes it easy for us to manage data and information. Our integrated model could be further used in mesh generation and numerical calculation, as shown in Figure 13. So the integrated model not only can be used for 


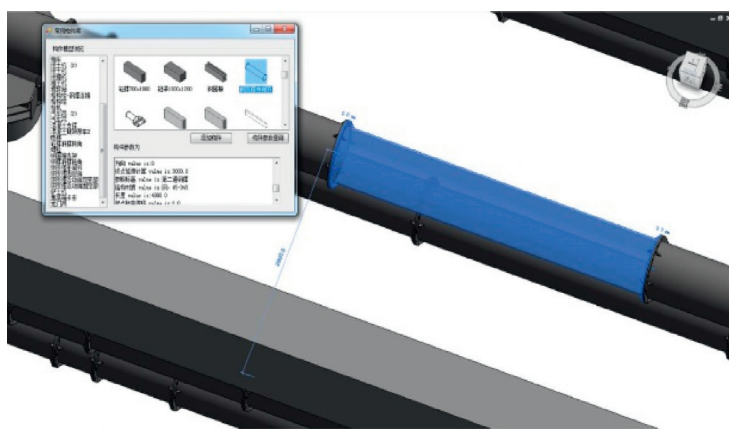

(a)

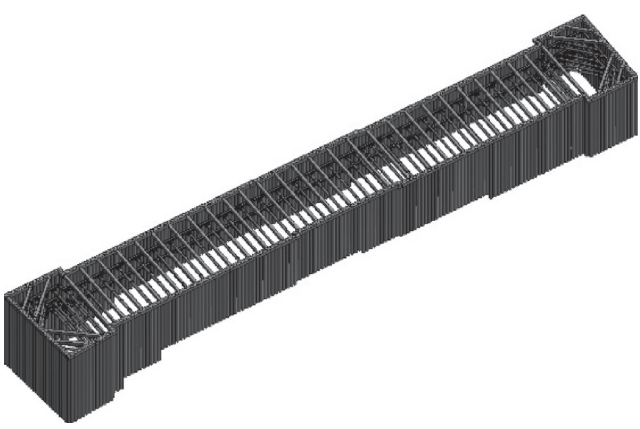

(b)

FIGURE 10: BIM model of foundation structure. (a) Call component library and search information. (b) Assembled BIM model.

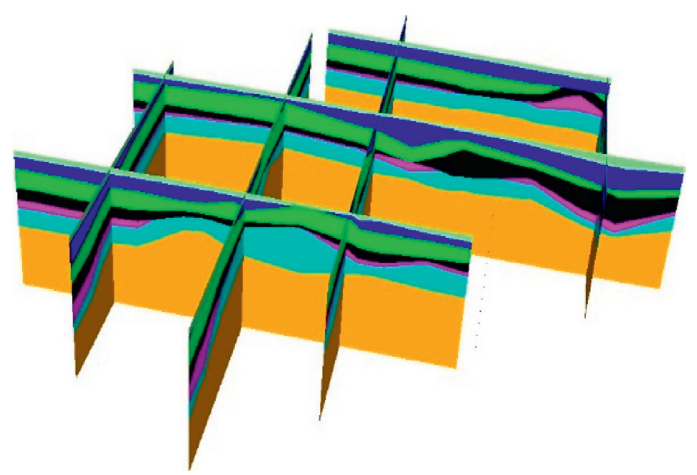

(a)

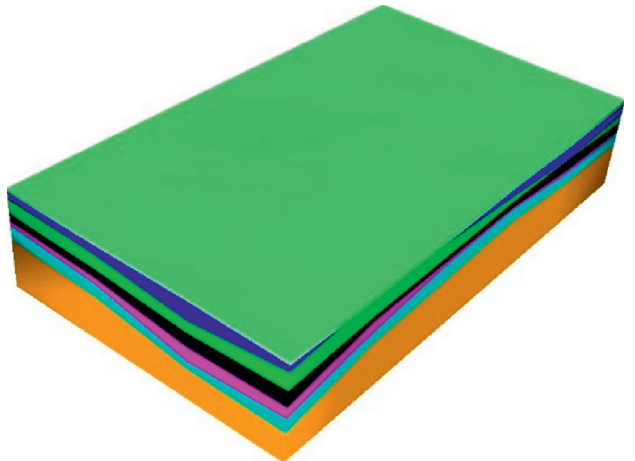

(b)

Figure 11: A geological model. (a) The profile of a geological model. (b) 3D geological model.

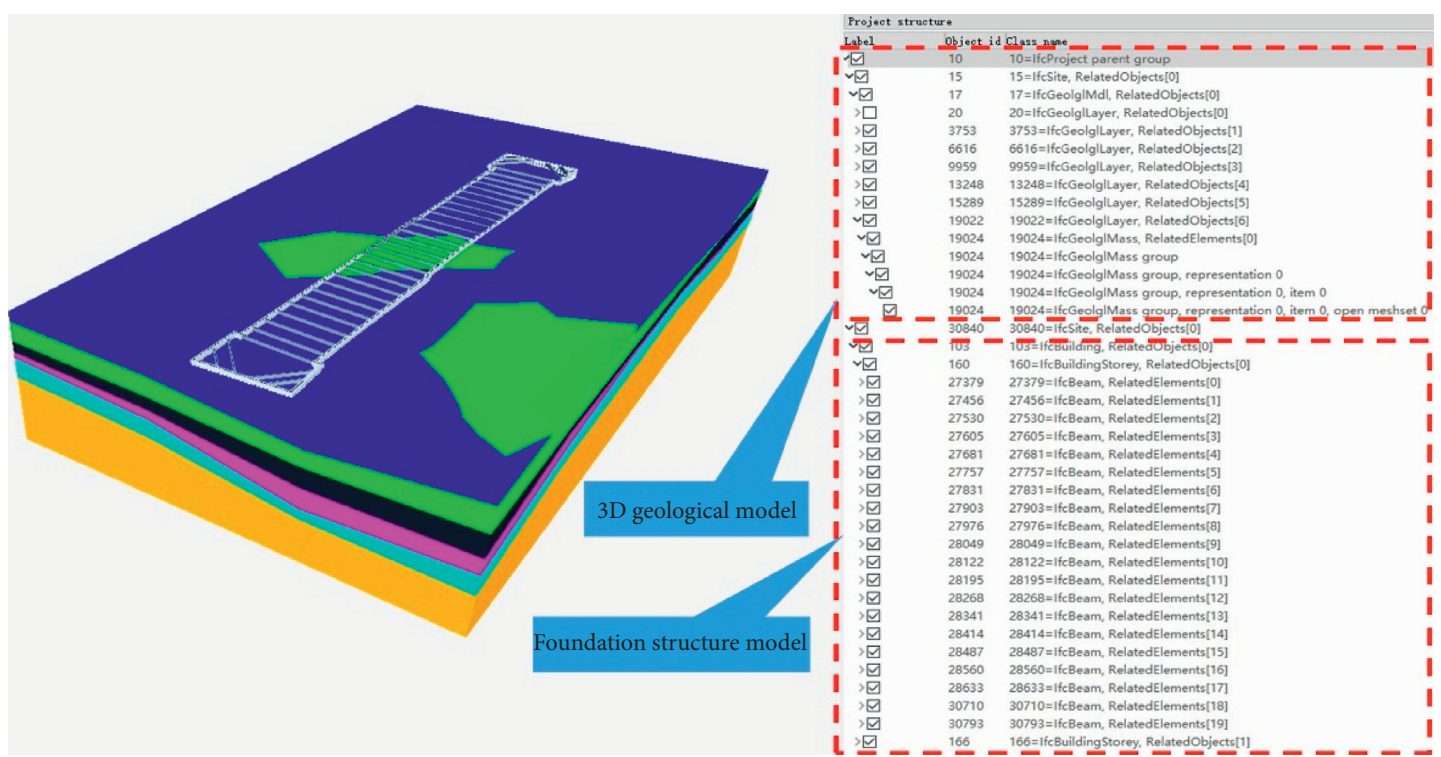

Figure 12: The integrated display of the geological model and the structure model.

visualization but also has the ability to be extended to generate numerical meshes for geotechnical computations. The integrated model of geotechnical engineering based on
BIM technology can serve the geotechnical design and effectively results in better information management for geotechnical engineering. 


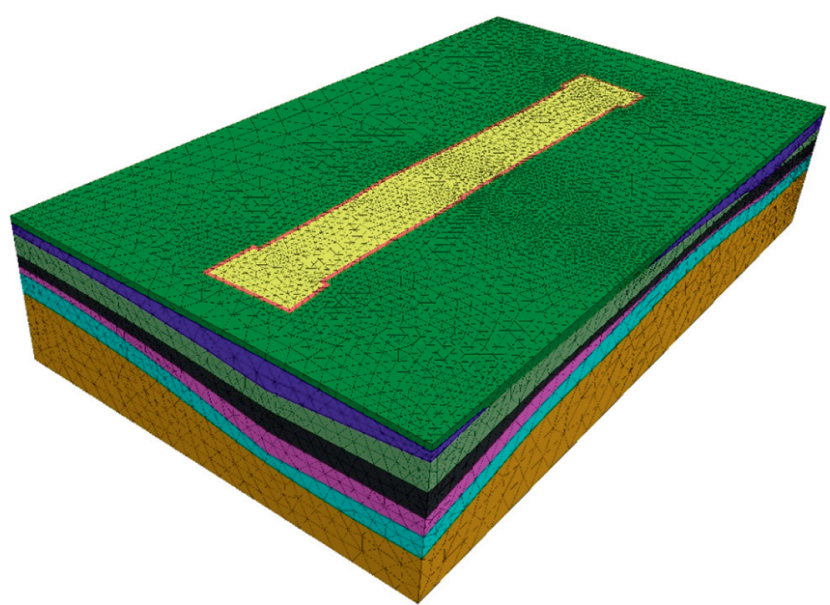

FIgURE 13: A numerical mesh model transformed from integrated BIM model.

\section{Conclusion}

In the process of geotechnical engineering construction, the information contained in geotechnical engineering cannot be well integrated because of the lack of unified data standards. According to the characteristics of geotechnical engineering objects, based on the existing IFC standard description mechanism, this paper adopts the method of extending IFC entity to describe geotechnical engineering objects such as geological model and geological structure model. Considering the fact that the geological structure model and building model have a lot in common, some geological structures can directly inherit and reference existing IFC entities, and the others that have not yet been included need to be newly added, so we have put forward a "Built-In Generation Schema" for geotechnical structure model. In view of the lack of definition of geological models in IFC, corresponding IFC entities and relationships need to be constructed from scratch, and hence a "Plug-In Extension Schema" for the geological model has been developed. On the basis of the realization of the data expression of geotechnical engineering information based on IFC standard, the basic data system of geotechnical engineering information model based on BIM technology has been formed to overcome the shortage of multisource data fusion.

Taking the diversity of foundation structure models into account, a "foundation structure model library" has been presented to store various basic components. Through parametric modeling, we have contributed to the modeling process and modeling method of the foundation structure model based on BIM technology. Additionally, the IFC extension for the geological model has been employed to the one-to-one mapping between the geological model and IFC model, thus realizing the output of the geological model based on the extended IFC standard. An integration platform, aimed to realize the integration and sharing of the geological model and geotechnical structure model based on the extended IFC standard, has been preliminarily developed. Based on proposed data generation mechanism under IFC framework, geological models and geotechnical structure models are integrated, so as to solve the problem of inconsistency of current data standards. Combined with the characteristics of geotechnical engineering, our integrated model is both "good-looking and useful," which not only can be visualized display but also can be utilized to generate numerical meshes for geotechnical computations.

The research in this paper lays a solid foundation for promoting the application of BIM technology in the geotechnical engineering field and also provides a feasible way and technical support for promoting the integration and sharing of geotechnical engineering information and carrying out geotechnical design and numerical analysis. It also will be dedicated to serving the digital twin model of geotechnical engineering.

In the future, researches on the integrated data model in the field of geotechnical engineering based on BIM technology will continue. In order to further realize the design and calculation of geotechnical engineering, there is a need to further study the interconversion between the integrated BIM model and finite element analysis model.

\section{Data Availability}

The data generated in this research are available from the corresponding author on request.

\section{Conflicts of Interest}

The authors declare that they have no conflicts of interest.

\section{Acknowledgments}

The research was supported by National Natural Science Foundation of China (Grants no. 52079135 and no. 51909259), the International Partnership Program of Chinese Academy of Sciences (Grant no. 131551KYSB20180042), the Science and Technology R\&D Project of China State Construction International Holdings Limited (Grant no. CSCI2020-Z-21), and Ningbo Public Welfare Science and Technology Planning Project (Grant no. 2019C50012). A special acknowledgement should be expressed to China-Pakistan 
Joint Research Center on Earth Sciences that supported the implementation of this study.

\section{References}

[1] M. H. Faber and M. G. Stewart, "Risk assessment for civil engineering facilities: critical overview and discussion," Reliability Engineering \& System Safety, vol. 80, no. 2, pp. 173-184, 2003.

[2] I. C. Cárdenas, S. S. H. Al-jibouri, J. I. M. Halman, and F. A. van Tol, "Capturing and integrating knowledge for managing risks in tunnel works," Risk Analysis, vol. 33, no. 1, pp. 92-108, 2013.

[3] Q. Z. Yu, L. Y. Ding, C. Zhou, and H. B. Luo, "Analysis of factors influencing safety management for metro construction in China," Accident Analysis \& Prevention, vol. 68, pp. 131-138, 2014.

[4] Y. Zhou, L. Y. Ding, and L. J. Chen, "Application of 4D visualization technology for safety management in metro construction," Automation in Construction, vol. 34, pp. 25-36, 2013.

[5] T. Vilutiene, D. Kalibatiene, M. R. Hosseini, E. Pellicer, and E. K. Zavadskas, "Building information modeling (BIM) for structural engineering: a bibliometric analysis of the literature," Advances in Civil Engineering, vol. 2019, Article ID 5290690, 19 pages, 2019.

[6] B. Becerik-Gerber, F. Jazizadeh, N. Li, and G. Calis, "Application areas and data requirements for BIM-enabled facilities management," Journal of Construction Engineering and Management, vol. 138, no. 3, pp. 431-442, 2012.

[7] L. Y. Ding, Y. Zhou, H. B. Luo, and X. G. Wu, "Using nD technology to develop an integrated construction management system for city rail transit construction," Automation in Construction, vol. 21, pp. 64-73, 2012.

[8] J. Shi, J. Dao, L. Jiang, and Z. Pan, "Research on IFC- and FDSbased information sharing for building fire safety analysis," Advances in Civil Engineering, vol. 2019, Article ID 3604369, 18 pages, 2019.

[9] T. Cerovsek, "A review and outlook for a 'Building Information Model' (BIM): a multi-standpoint framework for technological development," Advanced Engineering Informatics, vol. 25, no. 2, pp. 224-244, 2011.

[10] P. Calcagno, J. P. Chilès, G. Courrioux, and A. Guillen, "Geological modelling from field data and geological knowledge," Physics of the Earth and Planetary Interiors, vol. 171, no. 3, pp. 147-157, 2008.

[11] P. B. Scharling, E. S. Rasmussen, T. O. Sonnenborg, P. Engesgaard, and K. Hinsby, "Three-dimensional regionalscale hydrostratigraphic modeling based on sequence stratigraphic methods: a case study of the Miocene succession in Denmark," Hydrogeology Journal, vol. 17, no. 8, pp. 1913-1933, 2009.

[12] O. Kaufmann and T. Martin, "3D geological modelling from boreholes, cross-sections and geological maps, application over former natural gas storages in coal mines," Computers \& Geosciences, vol. 34, no. 3, pp. 278-290, 2008.

[13] R. Song, X. Qin, Y. Tao et al., "A semi-automatic method for 3D modeling and visualizing complex geological bodies," Bulletin of Engineering Geology and the Environment, vol. 78, no. 3, pp. 1371-1383, 2019.

[14] A. Zanchi, S. Francesca, Z. Stefano, S. Simone, and G. Graziano, "3D reconstruction of complex geological bodies: examples from the Alps," Computers \& Geosciences, vol. 35, no. 1, pp. 49-69, 2009.
[15] Z.-q. Luo, C.-y. Xie, J.-m. Zhou, N. Jia, X.-m. Liu, and H. Xu, "Numerical analysis of stability for mined-out area in multifield coupling," Journal of Central South University, vol. 22, no. 2, pp. 669-675, 2015.

[16] M. Sen and T. Duffy, "GeoSciML: development of a generic GeoScience markup language," Computers \& Geosciences, vol. 31, no. 9, pp. 1095-1103, 2005.

[17] W. Tegtmeier, S. Zlatanova, P. J. M. van Oosterom, and H. R. G. K. Hack, "3D-GEM: geo-technical extension towards an integrated 3D information model for infrastructural development," Computers \& Geosciences, vol. 64, pp. 126-135, 2014.

[18] H. Cheng, J. Chen, R. Chen, G. Chen, and Y. Zhong, "Risk assessment of slope failure considering the variability in soil properties," Computers and Geotechnics, vol. 103, pp. 61-72, 2018.

[19] G. Zheng, X. Yang, H. Zhou, Y. Du, J. Sun, and X. Yu, “A simplified prediction method for evaluating tunnel displacement induced by laterally adjacent excavations," Computers and Geotechnics, vol. 95, pp. 119-128, 2018.

[20] H. Cheng, J. Chen, and G. Chen, "Analysis of ground surface settlement induced by a large EPB shield tunnelling: a case study in Beijing, China," Environmental Earth Sciences, vol. 78, 2019.

[21] T. Ganbat, H. Chong, P. Liao, and Y. Wu, "A bibliometric review on risk management and building information modeling for international construction," Advances in Civil Engineering, vol. 2018, Article ID 8351679, 13 pages, 2018.

[22] N. Yabuki and Z. Li, Development of New IFC-BRIDGE Data Model and a Concrete Bridge Design System Using MultiAgents, Springer, Berlin, Germany, 2006.

[23] N. Yabuki, H. Machinaka, and Z. Li, A Cooperative Engineering Environment Using Virtual Reality with Sensory User Interfaces for Steel Bridge Erection, Springer, Berlin, Germany, 2006.

[24] Y. Zhou, Y. Wang, L. Ding, and P. E. D. Love, "Utilizing IFC for shield segment assembly in underground tunneling," Automation in Construction, vol. 93, pp. 178-191, 2018.

[25] S.-H. Lee and B.-G. Kim, "IFC extension for road structures and digital modeling," Procedia Engineering, vol. 14, no. 2, pp. 1037-1042, 2011.

[26] S.-H. Lee, S. I. Park, and J. Park, "Development of an IFCbased data schema for the design information representation of the NATM tunnel," KSCE Journal of Civil Engineering, vol. 20, no. 6, pp. 2112-2123, 2016.

[27] A. Costin, A. Adibfar, H. Hu, and S. S. Chen, "Building Information Modeling (BIM) for transportation infrastructure - literature review, applications, challenges, and recommendations," Automation in Construction, vol. 94, pp. 257-281, 2018.

[28] Y. Zhou, Z. Hu, and W. Zhang, "Development and application of an industry foundation classes-based metro protection information model," Mathematical Problems in Engineering, vol. 2018, Article ID 1820631, 20 pages, 2018.

[29] S. Providakis, C. D. F. Rogers, and D. N. Chapman, "Predictions of settlement risk induced by tunnelling using BIM and 3D visualization tools," Tunnelling and Underground Space Technology, vol. 92, p. 103049, 2019. 